\title{
Assessment of Nutrients in Seaweed Tank from Land Based Integrated Multitrophic Aquaculture Module
}

\author{
Sujjat Al Azad*, Abentin Estim, Saleem Mustafa, Milennie Vialantine Sumbing \\ Borneo Marine Research Institute, University Malaysia Sabah, Kota Kinabalu, Malaysia \\ Email:*sujjat@ums.edu.my
}

How to cite this paper: Al Azad, S., Estim, A., Mustafa, S. and Sumbing, M.V. (2017) Assessment of Nutrients in Seaweed Tank from Land Based Integrated Multitrophic Aquaculture Module. Journal of Geoscience and Environment Protection, 5, 137-147. https://doi.org/10.4236/gep.2017.58012

Received: July 3, 2017

Accepted: July 31, 2017

Published: August 3, 2017

Copyright $\odot 2017$ by authors and Scientific Research Publishing Inc. This work is licensed under the Creative Commons Attribution International License (CC BY 4.0).

http://creativecommons.org/licenses/by/4.0/

\begin{abstract}
Aquaculture industry is often generating waste that negatively impact to the environment. These wastes are rich in nutrients. Seaweed can utilize these waste nutrients. This experiment was conducted in a flow-through system (FTS) and a recirculation system (RS) in land-based integrated multi-trophic aquaculture module using seaweed Kappaphycus alvarezii as one of the components. The aim was to access the efficiency of the removal of nutrients in the integrated culture. Kappaphycus alvarezii was stocked at the density of 1 $\mathrm{kg} / \mathrm{tank}$ in the rectangular plastic tank with $500 \mathrm{~L}$ of seawater. The waste generated from integrated multi-trophic aquaculture tanks was directed towards $K$ alvarezii culture tank. Water samples from inlet, outlet and inside of the culture tanks were drawn to determine the nutrients, namely, total nitrogen $(\mathrm{mg} / \mathrm{L})$ and total phosphorus $(\mathrm{mg} / \mathrm{L})$. Total nitrogen and total phosphorus in the seaweed sample and from the sediment of culture tanks were also analyzed. The total nitrogen amounting to $59.5 \%$ and $61.6 \%$ nitrogen was taken up by $K$. alvarezii in FTS and RS culture tank, respectively. The phosphorus showed the highest deposition of $61.1 \%$ and $31.6 \%$ in the sediment of in FTS and RS culture tanks respectively, whereas only $5.5 \%$ and $3.4 \%$ of phosphorus were taken up by $K$. alvarezii from FTS and RS culture tanks, respectively. The percentage of nitrogen remained in water was comparatively higher by $14.2 \%$ and $27.5 \%$ than phosphorus by $8.3 \%$ and $23.0 \%$ in water of both FTS and RS culture tanks, respectively. These results indicated that this species seaweed is efficient in the removal of nitrogen from both FTS and RS culture tank.
\end{abstract}

\section{Keywords}

Kappaphycus alvarezii, Nutrients Removal, Flow-Through System and Recirculation System 


\section{Introduction}

The waste generated from aquaculture farm, although much smaller compare to that generated by the agricultural sector has contributed to environment degradation. In an intensive or semi-intensive system aquaculture species such as fish or shrimp assimilate only $23 \%-31 \%$ of nitrogen and $10 \%-13 \%$ of phosphorus from given feed, while the remaining $14 \%-53 \%$ of nitrogen and $39 \%-67 \%$ of phosphorus are execrated. These remain in water column or are deposited in sediment [1]. Both these nutrients are common effluents from aquaculture that occur as in particulate and dissolved forms. In aquaculture effluents, about 7\% $32 \%$ of total nitrogen (TN) and $30 \%-84 \%$ of total phosphorus (TP) and up to $27 \%$ of total carbon are bound in the particulate fraction and the remainder can be found in dissolved form [2]. The negative impact on the environment due to the release of effluents is related to eutrophication processes, especially in coastal and sheltered areas [3]. One of the best options to utilize these nutrients is to integrate the systems through cascading arrangements. By integrating fed aquaculture, the wastes generated from culture species become a resource for the other trophic level of species [4]. The generation of waste nutrient and their utilization by some stocked species is a sort of synergistic work. Balance of nutrients in culture tank proceeded various process. Nutrient introduced in each of integrated system must be utilized properly towards zero emission. Seaweed can be efficient in removal of dissolved inorganic and organic nutrients from effluent of intensive aquaculture system [4].

The use of seaweed integrated with fish culture has been studied in open water and land-based systems in Israel, Portugal, Brazil, and Indonesia [1] [5]. Seaweed performs better as a nitrogen absorber with ammonium than with nitrate which is excellent in the context of intensive fish aquaculture where most of the nitrogen is released as ammonium [6]. Seaweed (UIva lactucacan) removes 30\% of dissolved nutrient load from fishpond [7]. Shrimp (Penaeus monodon), mussel (Mytilus edulis) and seaweed Gracillaria is a good combination and recorded a reduction in the effluent of $72 \%$ of total nitrogen and $61 \%$ of total phosphorus in integrated system [3].

On the other hand, integrated multi-trophic aquaculture (IMTA) system has been proposed as a means of developing environmentally sound aquaculture practices and resource management through a balanced ecosystem approach. This system employs a combination of high nutrient uptake capacity seaweed and low trophic organisms which are herbivorous or omnivorous [4]. Most of the studies have focused on seaweeds integrated with fish culture [4] [8] [9] [10]. Studies have been conducted on the possibilities of IMTA systems of bivalves and seaweeds [11], but little information is available on the using spiny lobster as fed aquaculture species, sea cucumber as organic extractor and sea weed as the inorganic extractor in IMTA module. Thus this study was undertaken to assess the nutrient budget in the seaweed, Kappaphycus alvarezii culture tank in flowthrough and re-circulating integrated multi-trophic aquaculture systems. 


\section{Methodology}

Three $500 \mathrm{~L}$ water capacity rectangular tanks were used in this experiment. One tank was stocked with spiny lobster (Panulirus ornatus) for fed aquaculture species. The waste from spiny lobster tank was diverted to sea cucumber (Holothuria scabra) unit and finally waste of dissolved organic and inorganic nutrients collected in seaweed (Kappaphycus alvarezii) culture tank. Kappaphycus alvarezii was obtained from the supplier at Kampung Baru, Tuaran, Sabah, Malaysia, and transported to University Malaysia Sabah Shrimp Hatchery. The seaweed was acclimatized in the culture tank before start of the experiment. Stocking density was $1 \mathrm{~kg} / 400 \mathrm{~L}$ water. Pieces of $50 \mathrm{~g}$ of Kappaphycus alvarezii were arranged in a row and tied by using nylon cotton thread in the seaweed tank. Waste comprising of dissolved and particulate organic and inorganic nutrients from spiny lobster (Panulirus ornatus) and sea cucumber (Holothuria scabra) tanks were used as the source nutrients in seaweed cultivation tank.

The insitu water quality parameters were monitored every day morning and evening in Kappaphycus alvarezii tank by using digital YSI multi-probe equipment. The parameter includes, dissolved oxygen concentration $(\mathrm{mg} / \mathrm{L}), \mathrm{pH}$, temperature $\left({ }^{\circ} \mathrm{C}\right)$, water salinity (psu), and light intensity (lux). Water samples were collected at every two week interval from three locations, inflow of water to Kappaphycus alvarezii, water inside of culture tank and water sample outflow point of seaweed tank. Three beakers of $500 \mathrm{ml}$ were placed at the bottom of seaweed experimental tank and sediments were collected at the end of experiment. Collected sediments were placed in an oven at $60^{\circ} \mathrm{C}$ temperature until complete dryness. Samples were powdered and stored in a fridge in sealed plastic bag until analysis. Sample of seaweed was taken before start of the experiment and at the end of the experiment and placed in oven at $60^{\circ} \mathrm{C}$ temperature for drying. The dried seaweed was grinded into fine powder and stored in a sealed plastic bag. The bags containing samples were stored into a fridge until analysis.

\section{Analytical Parameters}

Total nitrogen $(\mathrm{mg} / \mathrm{L})$ and total phosphorus $(\mathrm{mg} / \mathrm{L})$ from the samples of water and sediment were analyses according to standard methods [12] and dried Kappaphycus alvarezii were analyzed with standard methods [13]. In brief, total nitrogen in water was determined by persulfate oxidation method followed by the spectrophotometric measurement. The total phosphorus in water sample was converted into soluble phosphorus (Orthophosphate) by digestion with a mixture of sulfuric acid and ammonium per-sulfate. Soluble phosphorus was then measured by the ascorbic acid method. Total nitrogen in the sediment and Kappaphycus alvarezii dry samples were digested with strong sulphuric acid and followed by distillation in Kjeltech auto-analyzer. Total phosphorous in sediment and also Kappaphycus alvarezii samples were analyzed by acid mixture digestion and spectrophotometric method.

Removal efficiency (RE\%) of nutrients was calculated according to formula 
described as below [14]:

$$
\mathrm{NRE}=\left[\left(M_{t}-M_{o}\right) / M_{o}\right] \times 100
$$

where: NRE refer as Nutrient Removal Efficiency, $M_{o}$ as initial nutrient concentration and $M_{t}$ as nutrient concentration at time $t$.

\section{Results}

The values of the insitu water quality parameters in the Kappaphycus alvarezii experimental tank were observed similar in both flow-through and recirculation systems as shown in Table 1. Thus, the influences of environmental parameters on the nutrients flux of this tank were negligible.

\subsection{Total Nitrogen Utilization in Kappaphycus alvarezii Tank}

Nutrient budget showed that the maximum percentage of total nitrogen was removed by Kappaphycus alvarezii in both FTS (59.55\%) and RS (61.6\%) systems. Total nitrogen remaining the inside tank water of RS (27.5\%) system was comparatively higher than the percentage of total nitrogen (14.2\%) obtained inside the tank of FTS system. On the other hand, the highest amount of $19.1 \%$ total nitrogen was obtained in sediment of FTS system, while only $6.35 \%$ of total nitrogen was recorded in sediment of RS system (Figure 1 and Figure 2).

\subsection{Total Phosphorus Utilization in Kappaphycus alvarezii Tank}

Nutrient budget showed that the maximum of percentage of total phosphorus remained in the sediment and accounted $61.1 \%$ and $31.6 \%$ in FTS and RS systems,

Table 1. The concentration of dissolved oxygen $(\mathrm{mg} / \mathrm{l}), \mathrm{pH}$, temperature $\left({ }^{\circ} \mathrm{C}\right)$, salinity (psu) and light intensity (lux) recorded from Kappaphycus alvarezii tank in flow-through system (FTS) and recirculation tank system (RS) (Values express as Mean \pm S.D).

\begin{tabular}{cccccc}
\hline Systems & DO $(\mathrm{mg} / \mathrm{l})$ & $\mathrm{pH}$ & Temperature $\left({ }^{\circ} \mathrm{C}\right)$ & Salinity $(\mathrm{psu})$ & Light intensity (lux) \\
\hline Flow through & $65.6 \pm 0.31$ & $8.07 \pm 0.04$ & $29.6 \pm 0.88$ & $31.2 \pm 0.09$ & $16641 \pm 47.1$ \\
Recirculation & $66.1 \pm 0.11$ & $8.10 \pm 0.04$ & $25.9 \pm 0.61$ & $33.2 \pm 0.18$ & $16323 \pm 48.8$ \\
\hline
\end{tabular}

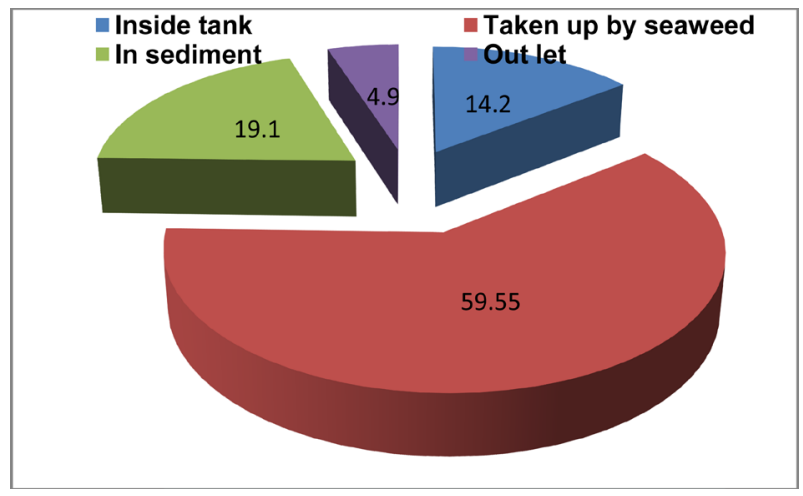

Figure 1. Utilization of total nitrogen (\%) in Kappaphycus alvarezii tank in a land based IMTA flow through system (FTS). 
respectively. The highest percentage in sediment was followed by estimation of total phosphorus in the range of $16.6 \%$ and $29.05 \%$ outlet point of FTS and RS systems, respectively. The lowest percentage of $5.55 \%$ and $3.41 \%$ phosphorus were removed by the seaweed in FTS and RS systems, respectively. Certain percentage of total phosphorus remained unaccounted in both FTS and RS systems compared to the total nitrogen these two systems (Figure 3 and Figure 4).

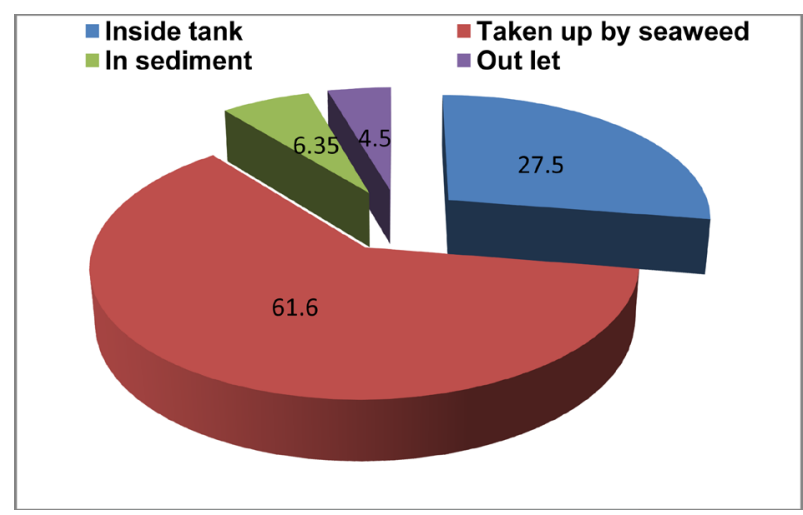

Figure 2. Utilization of total nitrogen (\%) in Kappaphycus alvarezii tank in a land based IMTA recirculation system (RS).

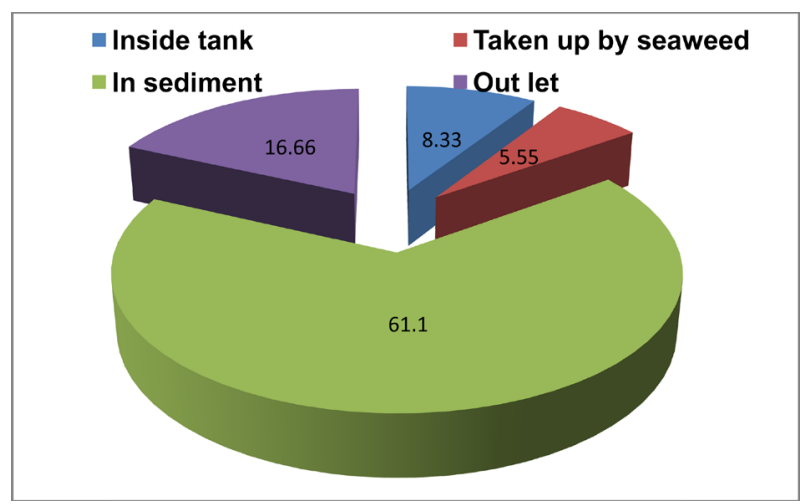

Figure 3. Utilization of total phosphorus (\%) in Kappaphycus alvarezii tank in a land based IMTA flow through system.

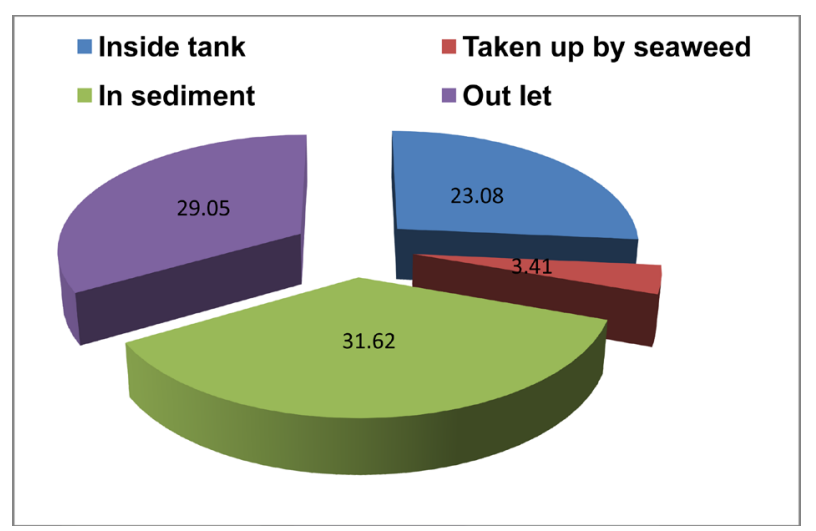

Figure 4. Utilization of total phosphorus (\%) in Kappaphycus alvarezii tank in a land based IMTA flow through system. 


\section{Discussion}

The efficacy of total nitrogen removal in FTS and RS system was $59.5 \%$ and $61.6 \%$, respectively. The removal efficacy of total nitrogen was observed to be the highest compared to removal of total phosphorus $(3.41 \%$ - 5.55\%) by Kappaphycus alvarezii. Nutrients like nitrogen and phosphorus in aquatic system are directly taken up by macro-algae for their growth. Seaweeds have high rates of productivity and they grow well in water bodies with higher nitrogen and other nutrients. Seaweeds are integrators of bio-available nutrients over time [7]. Among the nutrients Nitrogen is the primary one that limits seaweed growth, thus nitrogen uptake from water can control the growth of macro-algae. Typically, green macro algae take up nutrients faster per unit of biomass than thick thalli, the brown algae [15]. This result shows a better removal efficacy in assimilation of nitrogen excretory products from lobster fed tank by seaweed, Kappaphycus alvarezii in both FTS and RS systems. An estimated 17\% nitrogen removal efficiency could be easily achieved, but it will depend on the supply of dissolved inorganic nitrogen. Nitrogen removal efficiency was reported to vary widely $(10 \%-90 \%)$ in poly-culture systems [16]. The removal of total nitrogen from the aquaculture system was found to be $45 \%$ when treated with seaweed. Efficient nitrogen uptake even at low substrate concentrations has been reported for Ulva species [17]. Seaweeds show great species-specific variations in the nutrient uptake and their composition, which reflects the influence of environmental factors such as water temperature, salinity, light and availability of nutrients. Not only environmental factors, nutrient removal vary with seaweed species, habitat, maturity and as well as with the various phases of algal growth. Seaweed performs better as nitrogen absorber with ammonium than with nitrate which serves the purpose in intensive fish aquaculture where most of nitrogen is released as ammonium [6]. Tank cultivated Gracillaria could remove as much as $90 \%$ - 95\% of the ammonium in effluent waters released from salmon tanks [18]. Such rapid accumulation by seaweed has been documented to function even in different culture systems [19]. In both FTS and RT systems in this experiment, total nitrogen from the fed-based lobster culture is rapidly taken up by Kappaphycus alvarezii. It has been observed earlier that effluent of abalone (Haliotis tuberculata) culture tank divert into seaweed (Ulva lactuca) culture tank contained nitrogenous waste of which $58 \%$ was removed by seaweed [20].

In this experiment efficiently of phosphorus utilization by seaweed Kappaphycus alvarezii was observed lower than that of nitrogen by Kappaphycus alvarezii. harvesting accounted for $35.5 \%$ and $6.1 \%$ of the total nitrogen and total phosphorus input into the ponds in cage poly-culture of white shrimp with seaweed Kappaphycus alvarezii [5]. This experiment also confirmed that nutrient availability in culture tank was observed to be controlled by water management system. In water recirculation system nutrient flux was observed to increase of $27.5 \%$ and $23.08 \%$ in total nitrogen and total phosphorus, respectively compared to flow through system. Thus nitrogen uptake efficiency of seaweed in recircula- 
tion tank is slightly higher (61.6\%) in comparison with flow through system (59.5\%). The effects of water flow and nutrient availability influences the uptake efficiency. By increasing the water flow, nutrient flux will increase as well, which allows a high biomass production of nutrient-sufficient seaweeds. Nitrogen can be efficiently removed from water when in lower concentration and higher flow rate. The high flow rates are required in order to keep the nitrogen concentration at a constant level [21]. If the water flow is low, nutrients become limiting and seaweed biomass production decreases, but the nutrient uptake efficiency is higher [22]. Only the algae tissue did not account for all nitrogen removal from the cultivation media. This phenomenon was also described researcher [20] where the protein content of the harvested algae did not fully account for the total nitrogen removed from the system, but this was not observed in this experiment. The specific role of alternative pathways for nitrogen removal was also not studied in this experiment. Higher concentrations of nitrogen and phosphorus will be deposited in the tissue [23] but the excess nutrients in water do not necessarily lead to their high concentrations in tissues, even luxuriant consumption phenomena observed in seaweed [24]. In addition to that, the nutrient uptake efficiency sometimes was observed low and nutrient concentration remains high in the effluents. Nutrient uptake or removal efficiency depends on various physical parameters such as light, temperature, $\mathrm{pH}$ and salinity. The water temperature in the flow-through system remained fairly constant during the day because of the high flow rate through the fish culture and the algal tanks [25]. The greatest production for macro algae was found in $\mathrm{pH}$ values of 8.0 - 8.2 [26]. The salinity of $30 \%$ - $33 \%$ was suitable to the highest specific growth rate of $31 \%$ o [27]. However, nutrient availability was higher in the flow-through culture, resulting in greater total nutrient uptake and thereby more growth, as indicated by the greater final biomass in these cultures. The removal efficiency for total phosphorus $36 \%-50 \%$ in the flow-through system which was comparable with other experiments in which Kappaphycus alvarezii (27\%) and Ulva reticulate (33\%) have been used as biofilters in fish effluents [28].

The concentrations of nutrients in water depend on the vertical distribution of the macro-algae in the water column. Most of the nutrients regenerated were accumulated in the sediments. In fact, macro algae grew by taking up nutrients from the water and simultaneously decayed at the surface sediments. The sinks for total nitrogen in sediments of FTS and RS in present experiment were recorded $19.1 \%$ and $6.35 \%$, respectively. Negligible percentages of total nitrogen $(0.05 \%$ to $2.25 \%)$ remained unaccounted. Approximately $30 \%$ of the nitrogen unaccounted in intensive shrimp culture is assumed to be the nitrogen to the atmosphere as nitrogen or ammonia [29]. The highest percentage of total phosphorus (61.1\% in FTS and $31.62 \%$ in RS) was observed in sediment compared to total nitrogen. It can be assumed that this amount is lost through consumption by microbes or fixed in minerals in sediment, although this was not taken into consideration in this study. The nitrogen and phosphorus in the surface sedi- 
ment were normally had higher values than other layers because some soluble or granular matter containing nitrogen and phosphorus could be deposited on the sediment through flocculation, adsorption, sedimentation and so on [30]. Decrease in the concentration of total nitrogen and total phosphorus in water indicated that the significant amounts of nitrogen and phosphorus may be released from the sediment to form a new equilibrium between water and the sediment based on specific concentration gradients. The released nutrients will be absorbed by macro-algae. In intensive marine shrimp culture pond total phosphorus of $84 \%$ was retained in the sediments [29]. Major sources of nutrients in sediment are detritus and excreted product of feed species. In addition, some bacteria degrade the organic detritus in seaweed tank and release dissolved inorganic nutrients to the water. In well manage condition, $21 \%$ of nitrogen and $53 \%$ of $\mathrm{P}$ into the culture system accumulate in the bottom sediments [31].

Total phosphorus of out let water in this experiment was accounted of $16.6 \%$ and $29.1 \%$ in FTS and RS, respectively. This was discharged to environment in FTS or recycled back in RS. The marked increase in net phosphorus concentration in the water environments is considered to be a result of macro algal decomposition. In this experiment it is unclear what might have caused this increase in phosphorus in both systems. It is surprising that phosphorus was not efficiently removed from the water and $25 \%$ of it remained in water for incorporation into phosphorus-demanding macro algae [30]. On the other hand 8.35\% and $12.8 \%$ of TP remain unaccounted in FTS and RS respectively. In Intensive culture $42.8 \%$ of total phosphorus input for the monoculture and $43.4 \%$ for the poly-culture system were unaccounted [8]. Effluent water constituted $10 \%$ of TP loss in the budget and this is mainly bound in the suspended solid fraction. Thus, trapping of the suspended solid fraction is important to minimize its environmental impact [29].

\section{Conclusion}

Seaweed (Kappaphycus alvarezii) in land-based IMTA culture tank has potential to be used in order to improve nutrient utilization, especially total nitrogen and also to decrease nutrient discharge to the environment. It is necessary to study the other species combinations in IMTA to enhance the systems' nutrient assimilation performance.

\section{Acknowledgements}

We greatly appreciate the support of this work received grant from Integrated Multi-Trophic Aquaculture System (NRGS0001) and supporting staff of Borneo Marine Research Institute, University Malaysia Sabah, Kota Kinabalu, Sabah, Malaysia.

\section{References}

[1] Schuenhoff, A., Shpigel, M., Lupatsch, I., Ashkenazi, A., Msuya, F.E. and Neori, A. 
(2003) A Semi-Recirculating, Integrated System for the Culture of Fish and Seaweed. Aquaculture, 221, 167-181.

[2] Bergheim, A., Kristiansen, R. and Kelly, L. (1993) Treatment and Utilization of Sludge from Land Based Farms for Salmon. Proceedings of an Aquacultural Engineering Conference, Washington DC, 21-23 June 1993, 1134.

[3] Neori, A. and Shpigel, M. (2003) Using Algae to Treat Effluents and Feed Invertebrates in Sustainable Integrated Mariculture. World Aquaculture, 30, 46-51.

[4] Neori, A., Chopin, T., Troell, M., Buschmann, A.H., Kraemer, G.P., Halling, C., Shpigel, M. and Yarish, C. (2004) Integrated Aquaculture: Rationale, Evolution and State of the Art Emphasizing Seaweed Biofiltration in Modern Mariculture. Aquaculture, 231, 361-391.

[5] Lombardi, J.V., de Almeida-Marques, H.L., Pereira, R.T.L., Barreto, O.J.S. and de Paula, E.J. (2006) Cage Polyculture of the Pacific White Shrimp Litopenaeus vannamei and the Philippines Seaweed Kappaphycusalvarezii. Journal of Aquaculture, 258, 412-415.

[6] Carmona, R., Kraemer, G.P., Zertuche, J.A., Chanes, L., Chopin, T., Neefus, C. and Yarish, C. (2001) Exploring Porphyra Species for Use as Nitrogen Scrubbers in Integrated Aquaculture. Journal of Phycology, 37, 9-10.

[7] Troell, M.P., Halling, C., Nilsson, A., Buschmann, A.H., Kautsky, N. and Kautsky, L. (1997) Integrated Marine Cultivation of Gracilaria chilensis and Salmon Cage for Reduced Environmental Impact and Increase Economic Output. Aquaculture, 156, 45-61.

[8] Troell, M., Halling, C., Neori, A., Chopin, T., Buschmann, A.H., Kautsky, N. and Yarish, C. (2003) Integrated Mariculture: Asking the Right Questions. Aquaculture, 226, 69-90.

[9] Chopin, T., Buschmann, A.H., Halling, C., Troell, M., Kautsky, N., Neori, A., Kraemer, G., Zertuche-Gonzalez, J., Yarish, C. and Neefus, C. (2001) Integrating Seaweeds into Aquaculture Systems: A Key towards Sustainability. Journal of Phycology, 37, 975-986. https://doi.org/10.1046/j.1529-8817.2001.01137.x

[10] Xu, Y.J., Fang, J., Tang, Q., Lin, J. and Le, G. (2008) Improvement of Water Quality by the Macro Algae, Gracilaria lemaneiformis (Rhodophyta), near Aquaculture Effluent Outlets. Journal of World Aquaculture Society, 39, 549-555. https://doi.org/10.1111/j.1749-7345.2008.00180.x

[11] Langdon, C., Evans, F. and Demetropoulos, C. (2004) An Environmentally Sustainable, Integrated, Co-Culture System for Dulse and Abalone Production. Aquacultural Engineering, 32, 43-56.

[12] Parsons, T., Maita, Y. and Lalli, C. (1984) A Manual of Chemical and Biological Methods for Seawater Analysis. Pergaman Press, Oxford, New York.

[13] AOAC (2012) Official Methods of Analysis. 19th Edition, Association of Official Analytical Chemists, AOAC International, Mary Land.

[14] Weih, M. (2014) A Calculation Tool for Analyzing Nitrogen Use Efficiency in Annual and Perennial Crops. Agronomy, 4, 470-477.

https://doi.org/10.3390/agronomy4040470

[15] Valiela, I., McClelland, J., Hauxwell, J., Behr, P.J., Hersh, D. and Foreman, K. (1997) Macroalgal Blooms in Shallow Estuaries: Controls and Ecophysiological and Ecosystem Consequences. Limnology and Oceanography, 42, 1105-1118. https://doi.org/10.4319/lo.1997.42.5_part_2.1105 
[16] Chung, I.K., Kang, Y.H., Yarish, C., Kraemer, G.P. and Lee, J.A. (2002) Application of Seaweed Cultivation to the Bioremediation of Nutrient-Rich Effluent. Algae, 17, 187-194. https://doi.org/10.4490/ALGAE.2002.17.3.187

[17] Seema, C. and Jayasankar, R. (2005) Removal of Nitrogen Load in the Experimental Culture System of Seaweed and Shrimp. The Marine Biological Association of India, 47, 150-153.

[18] Buschmann, A.H., Troell, M., Kautsky, N. and Kautsky, L. (1996) Integrated Tank Cultivation of Salmonids and Gracillaria chilensis. Hydrobiology, 326-327, 75-82. https://doi.org/10.1007/BF00047789

[19] Cohen, I. and Neori, A. (1991) Ulva lactuca Biofilters for Marine Fishpond Effluent. I. Ammonium Uptake Kinetics and Nitrogen Content. Botanica Marina, 34, 475482. https://doi.org/10.1515/botm.1991.34.6.475

[20] Neori, A., Msuya, F.E., Shauli, L., Schuenhoff, A., Kopel, F. and Shpigel, M. (2003) A Novel Three-Stage Seaweed (Ulva lactuca) Biofilter Design for Integrated Mariculture. Journal of Applied Phycology, 15, 543-553.

https://doi.org/10.1023/B:JAPH.0000004382.89142.2d

[21] Nielsen, M.M., Bruhn, A., Rasmussen, M.B., Olesen, B., Larsen, M.M., Henrik, B. and Møller, H.B. (2012) Cultivation of Ulva lactuca with Manure for Simultaneous Bioremediation and Biomass Production. Journal of Applied Phycology, 24, 449458. https://doi.org/10.1007/s10811-011-9767-Z

[22] Hanisak, M.D. (1998) Seaweed Cultivation: Global Trends. World Aquaculture, 29, $18-21$.

[23] Kamer, K. and Fong, P. (2001) Nutrient Enrichment Ameliorates the Negative Effects of Reduced Salinity on the Green Macro alga Enteromorpha intestinalis. Marine Ecology Progress Series, 218, 87-93. https://doi.org/10.3354/meps218087

[24] Nascimento, A., Coelho-Gomes, C., Barbarino, E. and Lourenço, S.O. (2014) Temporal Variations of the Chemical Composition of Three Seaweeds in Two Tropical Coastal Environments. Open Journal of Marine Science, 4, 118-139. https://doi.org/10.4236/ojms.2014.42013

[25] Kübler, J.E. and Davison, I.R. (1993) High Temperature Tolerance of Photosynthesis in the Red Alga Chondrus crispus. Marine Biology, 117, 327-335. https://doi.org/10.1007/BF00345678

[26] Amat, M.A. and Braud, J.P. (1990) Ammonium Uptake by Chondrus crispus Stackhouse (Gigartinales, Rhodophyta) in Culture. Hydrobiologia, 204-205, 467471. https://doi.org/10.1007/BF00040272

[27] Neish, A.C., Shacklock, P.F., Fox, C.H. and Simpson, F.J. (1977) The Cultivation of Chondrus crispus. Factors Affecting Growth under Greenhouse Conditions. Canadian Journal of Botany, 55, 2263-2271. https://doi.org/10.1139/b77-256

[28] Hayashi, L., Yokoya, N.S., Ostini, S., Pereira, R.T.L., Braga, E.S. and Oliveira, E.C. (2008) Nutrients Removed by Kappaphycus alvarezii (Rhodophyta, Solieriaceae) in Integrated Cultivation with Fishes in Re-Circulating Water. Aquaculture, 277, 185191.

[29] Funge-Smith, S.J. and Briggs, M.R.P. (1998) Nutrient Budgets in Intensive Shrimp Ponds: Implication for Sustainability. Aquaculture, 164, 117-133.

[30] Fong, P., Boyer, K.E., Kamer, K. and Boyle, K.A. (2003) Influence of Initial Tissue Nutrient Status of Tropical Marine Algae on Response to Nitrogen and Phosphorus Additions. Marine Ecology Progress Series, 262, 111-123.

https://doi.org/10.3354/meps262111 
[31] Feng. Y.Y., Hou. L.C., Ping, N.X., Ling, T.D. and Kyo, C.I. (2004) Development of Mariculture and Its Impacts in Chinese Coastal Waters. Reviews in Fish Biology and Fisheries, 14, 1-10. https://doi.org/10.1007/s11160-004-3539-7

Submit or recommend next manuscript to SCIRP and we will provide best service for you:

Accepting pre-submission inquiries through Email, Facebook, LinkedIn, Twitter, etc. A wide selection of journals (inclusive of 9 subjects, more than 200 journals)

Providing 24-hour high-quality service

User-friendly online submission system

Fair and swift peer-review system

Efficient typesetting and proofreading procedure

Display of the result of downloads and visits, as well as the number of cited articles Maximum dissemination of your research work

Submit your manuscript at: http://papersubmission.scirp.org/

Or contact gep@scirp.org 